\title{
The association between urinary placental protein 13 and soluble fms-like tyrosine kinase-1 in preeclamptic women in the third trimester of pregnancy
}

\author{
Nesreen A. Nasser ${ }^{1}$, Rayah S. Baban ${ }^{1}$, , May F. Al-Habib ${ }^{2}$ and Risala A. Jameel ${ }^{3}$ \\ ${ }^{1}$ Department of Chemistry and Biochemistry, College of Medicine, Al-Nahrain University, Baghdad, Iraq \\ Department of Anatomy, Histology and Embryology, College of Medicine, Al-Nahrain University, Baghdad, Iraq \\ Al-Immamain Al-Kadhimain Medical City, Ministry of Health, Baghdad, Iraq
}

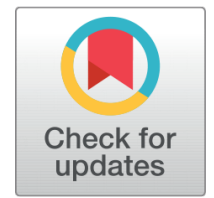

Received 03-10-2020

Revised 17-10-2020

Accepted 21-12-2020

Published 28-12-2020

Corresponding Author

Nesreen A. Nasser nena-

nena1987ahmednena@yahoo.com

Department of Chemistry and

Biochemistry, College of

Medicine, Al-Nahrain University,

Baghdad, Iraq

DOI https://doi.org/10.47419/

bjbabs.v1i01.31

\section{Pages: 49-55}

Distributed under

the terms of the Creative

Commons

Attribution-NonCommercial 4.0 International (CC-BY-NC 4.0), which permits use for any non-commercial purpose, distribution, and reproduction in any medium, provided that the original work is properly cited.

Copyright: (C) 2020 Nesreen A. Nasser, Rayah S. Baban, May F. Al-Habib, Risala A. Jameel

\section{ABSTRACT}

Background: Preeclampsia (PE) is diagnosed after 20 weeks of gestation. This multisystem disorder affects $2-7 \%$ of pregnant women. PE is a serious complication of pregnancy and one of the main causes of maternal and neonatal mortality and morbidity in the world. The inadequate placentation process results in a change in anti-angiogenic factors levels, such as placental protein 13 (PP13) and soluble fms-like tyrosine kinase 1 (sFlt-1).

Objectives: To investigate the correlation between urinary PP13 and sFlt-1 in preeclamptic women in their third trimester of pregnancy.

Methods: A case-control study was carried out from August 2018 till January 2019. Urine samples were collected from pregnant women at Al-Elweyia Hospital, Al-Hakeem Hospital, and Al- Imamain Al-Kadhimain Medical City (in Baghdad, Iraq). The patients' group include fifty women with PE in the third trimester (25 mild and 25 severe). Fifty healthy pregnant women (at their third trimester of pregnancy) were studied as a control group.

Results: The mean urinary PP13 levels were decreased in women with PE significantly $(p \leq 0.05)$ (mild and severe) compared with healthy women $(43.44 \pm 4.914 \mathrm{pg} / \mathrm{ml}, 33.34 \pm 1.863 \mathrm{pg} / \mathrm{ml}$, and $51.84 \pm 2.60 \mathrm{pg} / \mathrm{ml})$ respectively. Also, urinary sFlt-1 concentrations were decreased non-significantly $(p>0.05)$ in women with PE (mild and severe) compared with healthy women $(5.71 \pm 0.414 \mathrm{ng} / \mathrm{ml}$, $5.31 \pm 0.38 \mathrm{ng} / \mathrm{ml}$ and $6.01 \pm 0.282 \mathrm{ng} / \mathrm{ml})$, respectively.

Conclusions: Urinary PP13 and sFlt-1 levels in the third trimester of pregnancy were significantly correlated with the severity of PE, and urinary levels of PP13 were found to be decreased significantly in patients with PE than in healthy pregnant women in the $3^{\text {rd }}$ trimester of pregnancy.

Keywords galectin 13, placental protein 13, PP13, preeclampsia, soluble fms-like tyrosine kinase-1

\section{OPEN ACCESS}




\section{INTRODUCTION}

Preeclampsia (PE) is a pregnancy-associated multisystem disorder that complicates 2$10 \%$ of pregnancies in the western world. It is accompanied by a neonatal and perinatal mortality rate of $10 \%$ worldwide. ${ }^{1}$ Early-onset PE (i.e., PE requiring delivery before 34 weeks of gestation) is associated with an increased risk of both short- and long-term maternal complications and perinatal mortality and morbidity. ${ }^{2}$ The diagnosis is mainly based on elevated blood pressure (BP), especially new-onset hypertension (systolic blood pressure $\geq$ $140 \mathrm{mmHg}$, or diastolic $\geq 90 \mathrm{mmHg}$ ), with proteinuria or other manifestations such as renal impairment, thrombocytopenia, hepatic dysfunction, pulmonary edema, or cerebral/ visual disturbances. ${ }^{3}$ The clinical features of $\mathrm{PE}$ are proteinuria and hypertension that occur after 20 weeks of gestation in women who were not previously diagnosed to be hypertensive. Other signs and symptoms of PE are edema and headache. ${ }^{4}$

Placental protein 13 (PP13 or Galectin-13) is an exclusive protein expressed by the placenta. It plays a significant role in adhesion of the placenta to the uterus and expansion of maternal arteries by remodeling. ${ }^{5}$ In addition, PP13 is one of the 56 known placental proteins identified so far; it is a $32-\mathrm{kDa}$ homodimer protein and was purified from the placenta. ${ }^{5}$ It binds to $\beta$-galactoside residues of several proteins on the cell surface, cytoskeleton, and extracellular matrix, thereby generating various responses such as immune responses and influencing other functions like apoptosis and molecular recognition. ${ }^{6}$ The availability of the purified native and recombinant PP13 have stimulated the generation of various polyand monoclonal antibodies, followed by the development of an ELISA immune-diagnostic kit, with these tools in hands, a comparative analysis of PP13 levels in maternal blood was conducted in many studies. ${ }^{7}$

The soluble fms-like tyrosine kinase 1 (sFlt-1) is a splice variant of the receptor 1 for vascular endothelial growth factor A (VEGF-A) that lacks the cytoplasmic and transmembrane domains. By binding to its circulating ligand with high affinity, sFlt-1 inhibits the VEGF-A pathway and impairs endothelial cell homeostasis. ${ }^{8}$ It is also known as a soluble receptor for VEGFs, and a protein that binds and decreases the concentrations of circulating VEGF and PlGF. ${ }^{9}$

This study was aimed to evaluate the potential use of PP13 and soluble fms-like tyrosine kinase-1 as biomarkers to predict the risk of developing PE and assess the severity.

\section{METHODS}

\section{Study design and participants}

This case-control study was conducted on 102 pregnant women in the period between August 2018 and January 2019. Urine samples of pregnant women were collected at the Al-Elweyia Hospital, Al-Hakeem Hospital, and Al- Imamain Al-Kadhimain Medical City. The practical part was conducted at the Department of Chemistry and Biochemistry and the Department of Anatomy, Histology and Embryology, College of Medicine, Al-Nahrain 
University, Baghdad, Iraq. Patients with chronic hypertension, gestational hypertension, renal and liver diseases, diabetes mellitus, smokers, fetal structural anomalies, multiple pregnancies, intrauterine fetal growth restriction from other causes, heart failure, inflammatory disorders, elderly pregnants, infectious disease, endocrine disease, HELLP syndrome, and collagen vascular disease were excluded from the study.

This research was approved by the Institutional Review Board (IRB) at the College of Medicine, Al-Nahrain University; and before participation, each participant was given an idea about the study and her written informed consent was taken. All pregnant women included in this study were in the third trimester of pregnancy.

\section{Biochemical analysis}

A random urine sample was collected in a sterile urine collection cup. Pregnant women were instructed to discard the first $20-25 \mathrm{~mL}$ of urine, and about sixty $\mathrm{mL}$ from the mid urine stream were collected. The collected specimen was stored in Eppendorf tubes at $80^{\circ} \mathrm{C}$ until analysis of placental protein 13 (placental protein 13), soluble fms like tyrosine kinase-1 (sFlt-1) concentrations. According to the manufacturer instructions, levels of sFlt1 and placental protein 13 were measured with a commercially available enzyme-linked immunosorbent assay (ELISA) (Bioassay technology laboratory).

\section{Statistical analysis}

Data were analyzed by statistical packages of SPSS 18.5 (Statistical Packages for Social Sciences-version 18.5). All data were presented as a mean \pm SEM. Statistical differences between data of patients and control groups were determined according to the student's t-test or one-way analysis of variance (ANOVA) as aproperiate. Correlation between the variables was performed by Spearman correlation coefficient. $P$ values were significant if it is $\leq 0.05$.

\section{RESULTS}

Table 1 illustrates the age of the patients' groups (mild and severe PE) and controls. The mean \pm SEM of maternal age for the pregnant control group and patients groups (mild and severe PE) were $29.28 \pm 1.08$ years, $29.84 \pm 1.70$ years, and $29.85 \pm 1.27$ years, respectively. No significant difference $(p>0.05)$ was found among all study groups.

The PP13 levels of control pregnant and patient groups (mild and severe PE) at the third trimester of pregnancy were $51.84 \pm 2.60 \mathrm{pg} / \mathrm{ml}, 43.44 \pm 4.91 \mathrm{pg} / \mathrm{ml}$, and $33.34 \pm 1.86 \mathrm{pg} / \mathrm{ml}$, respectively. There was a significant difference increases $(p=0.001)$ in the mean of urine PP13 between the patient's group (mild and severe) and control group; there were sig- 
Table 1 The a ge (mean \pm SEM) of participants among study groups

\begin{tabular}{llll} 
Control & Mild & Severe & $\boldsymbol{P}$-value \\
$29.28 \pm 1.08$ & $29.84 \pm 1.70$ & $29.85 \pm 1.27$ & $0.931^{N S}$ \\
\hline
\end{tabular}

nificant differences increases ( $p=0.022$ ) between the control pregnant group versus mild preeclamptic group in the third trimester of pregnancy; also there were a highly significant difference increases $(p=0.002)$ between the control pregnant versus severe preeclamptic group (Table 2$)$. At the same time, there was no significant difference $(p=0.062)$ between the mild preeclamptic group versus the severe PE group in the third trimester of pregnancy.

The sFlt-1 levels for control pregnant and patient groups (mild and severe PE) at the third trimester were $6.01 \pm 0.282 \mathrm{ng} / \mathrm{ml}, 5.71 \pm 0.414 \mathrm{ng} / \mathrm{ml}$, and $5.31 \pm 0.38 \mathrm{ng} / \mathrm{ml}$, respectively. There was no significant difference in mean of urine sFlt-1 for patients groups (mild and severe PE) against the control group, mild preeclamptic group against control pregnant group, severe preeclamptic against control pregnant, severe preeclamptic group against the mild group in the third trimester (Table 2).

\begin{tabular}{|c|c|c|c|c|c|c|}
\hline & & Mean \pm SE & $P$ value* & $P$ value** & $P$ value ${ }^{* * *}$ & $P$ value ${ }^{* * * *}$ \\
\hline \multirow{4}{*}{$\begin{array}{c}\text { PP13 } \\
(\mathrm{pg} / \mathrm{ml})\end{array}$} & Control & $51.84 \pm 2.60$ & $0.001^{S}$ & $0.022^{S}$ & $0.002^{S}$ & $0.062^{N S}$ \\
\hline & All PE & $38.39 \pm 2.717$ & & & & \\
\hline & Mild PE & $43.44 \pm 4.914$ & & & & \\
\hline & Severe PE & $33.34 \pm 1.863$ & & & & \\
\hline \multirow{4}{*}{$\begin{array}{c}\text { sFlt-1 } \\
\text { (ng/ml) }\end{array}$} & Control & $6.01 \pm 0.282$ & $0.498^{N S}$ & $0.396^{N S}$ & $0.717^{N S}$ & $0.299^{N S}$ \\
\hline & All PE & $5.50 \pm 0.658$ & & & & \\
\hline & Mild PE & $5.71 \pm 0.414$ & & & & \\
\hline & Severe PE & $5.31 \pm 0.38$ & & & & \\
\hline
\end{tabular}

${ }^{*}$, comparison between controls and all PE patients (unpaired $t$-test); ${ }^{* *}$, comparison between controls and mild PE patients (unpaired $t$-test); ${ }^{* *}$, comparison between controls and severe PE patients (unpaired $t$-test); $* * * *$, comparison between mild and severe PE patients (unpaired $t$-test)

\section{DISCUSSION}

Galactin 13 (or PP13) is a small protein $(32 \mathrm{kD})$ produced by the placenta, specifically the syncytiotrophoblast. It binds to a protein on the extracellular matrix between the placenta and the endometrium, is thought to be involved in placental implantation and maternal vascular remodeling. Recently this protein has been attracted as a potential marker for early PE diagnosis. ${ }^{10}$ In this study, the maternal urine levels of the placental protein 13 were highly significant decreases in preeclamptic patients groups (mild and severe PE) compared 
to controls pregnant.

Decreased levels of PP13 have been found in patients who developed PE. In a study by Nicolaides et al. ${ }^{11}$ in patients with severe PE who gave birth before 34 weeks, the placental protein 13 serum levels were lower than in the normotensive individuals. They suggested that effective screening for PE requiring delivery before 34 weeks can potentially be provided by assessment of a combination of maternal serum PP13 and uterine artery Doppler in the first trimester of pregnancy. ${ }^{12}$

Regarding urinary placental protein 13 and to our knowledge, the present study is the first one concerning the level of urinary placental protein 13 in preeclamptic women at their $3^{\text {rd }}$ trimester. The present study found a decrease in urinary soluble fms like tyrosine kinase -1 in PE (mild and severe) compared with the pregnant control group in the third trimester. A similar result was reported by many studies. ${ }^{13}$

In a study conducted by Tang et al. (2017), ${ }^{13}$ serum and urinary sFlt-1 in severe PE patients were higher than those in the mild PE group, and measurements from mild PE patients were significantly higher than controls $(p<0.01)$, in that the elevated levels of sFlt1 can modify the endothelial integrity of blood vessels, causing hepatic edema and hypertension and proteinuria encountered in preeclamptic patients. Also, blood-brain-barrier damage may occur, leading to brain edema. This aberrant angiogenesis and hypertension are the hallmarks of PE. ${ }^{14}$

Placental overexpression of $s$ Flt1, specifically in the fetal derived trophoblast cells, was implicated as the underlying cause of PE.

\section{DECLARATIONS}

\section{Authors' contributions}

All authors have equally contributed to this work. They were all reviewed and approved this paper before publication.

\section{Conflict of interest}

The authors declare that there is no conflict of interest.

\section{Ethical approvals}

This research was approved by the Institutional Review Board (IRB) at the College of Medicine, Al-Nahrain University; and before participation, each participant was given an idea about the study and her written informed consent was taken.

\section{Data availability}

The data associated with this work can be requested from the corresponding author.

\section{Funding resources}

This work was't receive any fund. 


\section{REFERENCES}

1. Hitti J, Sienas L, Walker S, Benedetti TJ, Easterling T. Contribution of hypertension to severe maternal morbidity. Am J Obstet Gynecol. 2018;219(4):405.e1-405.e7. Available from: 10.1016/j.ajog.2018.07.002.

2. Stevens W, Shih T, Incerti D, Ton TGN, Lee HC, Peneva D, et al. Short-term costs of preeclampsia to the United States health care system. Am J Obstet Gynecol. 2017;217(3):237-248.e16. Available from: 10.1016/j.ajog.2017.04.032.

3. Sones JL, Davisson RL. Preeclampsia, of mice and women. Physiol Genomics. 2016;48(8):565-572. Available from: 10.1152/physiolgenomics.00125.2015.

4. ACOG. ACOG Practice Bulletin No. 202: Gestational Hypertension and Preeclampsia. Obstet Gynecol. 2019;133(1):1. Available from: 10.1097/AOG. 0000000000003018.

5. Sammar M, Drobnjak T, Mandala M, Gizurarson S, Huppertz B, Meiri H. Galectin 13 (PP13) facilitates remodeling and structural stabilization of maternal vessels during pregnancy. Int J Mol Sci. 2019;20. Available from: 10.3390/ijms20133192.

6. Hod T, Cerdeira AS, Karumanchi SA. Molecular mechanisms of preeclampsia. Cold Spring Harb Perspect Med. 2015;5(10):a023473-a023473. Available from: 10.1101/ cshperspect.a023473.

7. Maymon R, Trahtenherts A, Svirsky R, Melcer Y, Madar-Shapiro L, Klog E, et al. Developing a new algorithm for first and second trimester preeclampsia screening in twin pregnancies. Hypertens Pregnancy. 2017;36(1):108-115. Available from: 10.1080/10641955.2016.1242605.

8. Dupont V, Kanagaratnam L, Goury A, Poitevin G, Bard M, Julien G, et al. Excess soluble fms-like tyrosine kinase 1 correlates with endothelial dysfunction and organ failure in critically ill coronavirus disease 2019 patients. Arch Clin Infect Dis. 2020;p. 1834-1837. Available from: 10.1093/cid/ciaa1007.

9. Phipps EA, Thadhani R, Benzing T, Karumanchi SA. Pre-eclampsia: pathogenesis, novel diagnostics and therapies. Nat Rev Nephrol. 2019;15(5):275-289. Available from: 10.1038/s41581-019-0119-6.

10. Gadde R, Dayanand CD, Sheela SR. Placental protein 13: An important biological protein in preeclampsia. J Circ Biomark. 2018;7:1-16. Available from: 10.1177/ 1849454418786159.

11. Nicolaides KH, Bindra R, Turan OM, Chefetz I, Sammar M, Meiri H, et al. A novel approach to first-trimester screening for early pre-eclampsia combining serum PP-13 and Doppler ultrasound. Ultrasound Obstet Gynecol. 2006;27(1):13-17. Available from: 10.1002/uog.2686.

12. Kane SC. First trimester screening for pre-eclampsia. Obstet Med. 2016;9(3):106112. Available from: $10.1177 / 1753495 \times 16649074$.

13. Tang $\mathrm{P}, \mathrm{Xu}$ J, jun Xie B, mei Wang Q. Use of serum and urinary soluble sFlt-1 and PLGF in the diagnosis of preeclampsia. Hypertens Pregnancy. 2017;36(1):48-52. Available from: 10.1080/10641955.2016.1237642. 
14. Gurnadi JI, Mose J, Handono B, Satari MH, Anwar AD, Fauziah PN, et al. Difference of concentration of placental soluble fms-like tyrosine kinase-1 (sFlt-1), placental growth factor (PlGF), and sFlt-1/PlGF ratio in severe preeclampsia and normal pregnancy. BMC Res Notes. 2015;8(1):534. Available from: 10.1186/s13104-015-1506-0. 